\title{
Safety and efficacy of plerixafor dose escalation for the mobilization of CD34+ hematopoietic progenitor cells in patients with sickle cell disease: interim results
}

Farid Boulad, ${ }^{1,2}$ Tsiporah Shore, ${ }^{3}$ Koen van Besien, ${ }^{3}$ Caterina Minniti, ${ }^{4}$ Mihaela Barbu-Stevanovic, ${ }^{5}$ Sylvie Wiener Fedus, ${ }^{6}$ Fabiana Perna, ${ }^{2}$ June Greenberg, ${ }^{7}$ Danielle Guarneri, ${ }^{7}$ Vijay Nandi, ${ }^{5}$ Audrey Mauguen, ${ }^{8}$ Karina Yazdanbakhsh, ${ }^{5}$ Michel Sadelain ${ }^{2}$ and Patricia A. Shi ${ }^{4,5}$

${ }^{1}$ Department of Pediatrics, BMT Service, Memorial Sloan Kettering Cancer Center, New York; ${ }^{2}$ Center for Cell Engineering, Memorial Sloan Kettering Cancer Center, New York; ${ }^{3}$ Bone Marrow and Hematopoietic Stem Cell Transplant Program, Weill Cornell Medicine/ New York Presbyterian Hospital, New York; ${ }^{2}$ Sickle Cell Program, Division of Hematology, Albert Einstein College of Medicine, Bronx; ${ }^{5}$ Lindsley F. Kimball Research Institute, New York Blood Center, NY; ${ }^{\circ}$ Laboratory Medicine, Memorial Sloan Kettering Cancer Center, New York; ${ }^{7}$ Division of Hematology and Oncology, Weill Cornell Medicine /New York Presbyterian Hospital, NY and ${ }^{8}$ Department of Epidemiology and Biostatistics, Memorial Sloan Kettering Cancer Center, New York, NY, USA

An incorrect version of sentence appared on May 2018 Issue, pages 773.

Our target goal of mobilizing at least $30 \mathrm{CD} 34^{+}$cells/ $\mu \mathrm{L}$ was, however, reached in only $50 \%$ of patients given the plerixafor dose of $80 \mu \mathrm{g} / \mathrm{kg}, 33 \%$ of patients given $160 \mu \mathrm{g} / \mathrm{kg}$, and $33 \%$ of patients given $240 \mu \mathrm{g} / \mathrm{kg}$.

\section{The corrected version of sentence is published below.}

Our target goal of mobilizing at least $30 \mathrm{CD} 34^{+}$cells $/ \mu \mathrm{L}$ was, however, reached in only $50 \%$ of patients given the plerixafor dose of $80 \mu \mathrm{g} / \mathrm{kg}, 67 \%$ of patients given $160 \mu \mathrm{g} / \mathrm{kg}$, and $67 \%$ of patients given $240 \mu \mathrm{g} / \mathrm{kg}$.

An incorrect version of sentence appared on May 2018 Issue, pages 777.

Eight of 15 patients (53\%) with SCD treated with plerixafor reached the peripheral blood CD34 cell target count of at least $30 \mathrm{CD} 34^{+}$cells $/ \mu \mathrm{L}$, including three of six patients treated at a dose of $240 \mu \mathrm{g} / \mathrm{kg}$.

\section{The corrected version of sentence is published below.}

Nine of 15 patients (60\%) with SCD treated with plerixafor reached the peripheral blood CD34 cell target count of at least $30 \mathrm{CD} 34^{+}$cells $/ \mu \mathrm{L}$, including four of six patients treated at a dose of $240 \mu \mathrm{g} / \mathrm{kg}$. 